\title{
Theoretical Study on the Protonation of AZA-Aromatics
}

\author{
Peter van de Weijer and Douwe van der Meer \\ Chemical Physics Laboratory, Twente University of Technology, Enschede, The Netherlands
}

\author{
Johan L. Koster
}

Theoretical Chemistry Group, Rijksuniversiteit, Utrecht, The Netherlands

Received September 2, 1974/March 10, 1975

The protonation of azanaphthalenes and azabenzenes has been studied theoretically using $\mathrm{CNDO} / 2$ wavefunctions and perturbation theory in order to examine the correlation between $\mathrm{pK}_{\mathrm{a}}$ values and quantum-mechanical quantities.

Key words: Aza-aromatics, protonation of $\sim$

\section{Introduction}

Much attention has been given in the past to the theoretical study of protonation reactions [1-3]. These early works were rather limited, because of the use of very simplified methods, mainly $\pi$-electron theories. In the last ten years, however, more advanced methods have become available, semi-empirical as well as $a b$ initio, which have been used for a study on this subject [4-9]. In this paper we present the results of a theoretical study on the protonation of azaaromatics. This study, which is based on the CNDO/2 method and perturbation theory, is concerned with the correlation between the experimentally determined $\mathrm{pK}_{\mathrm{a}}$ values of the azanaphthalenes [10] and the theoretical calculations.

\section{Theory}

The energy change in solution $\left(\Delta E_{l}\right)$ accompanying the proton transfer reaction

$$
\mathrm{RH}^{+} \rightarrow \mathrm{R}+\mathrm{H}^{+}
$$

can be calculated from the gas phase protonation energy $\Delta E_{g}$ and the solvation energy terms $E_{s}$ as follows:

$$
\Delta E_{l}=-\Delta E_{g}+E_{s}(\mathrm{R})-E_{s}\left(\mathrm{RH}^{+}\right)+E_{s}\left(\mathrm{H}^{+}\right)
$$

where $\Delta E_{g}$ is defined by:

$$
\Delta E_{g}=E_{g}\left(\mathrm{RH}^{+}\right)-E_{g}(\mathrm{R}) .
$$

In our study $\Delta E_{g}$ has been calculated quantum-mechanically (see below). The solvation energies of $\mathrm{R}$ and $\mathrm{RH}^{+}$are obtained using the classical model of Hylton et al. [11] and $E_{s}\left(\mathrm{H}^{+}\right)$is a constant known from experiment. 
In view of the large size of the molecules to be studied, $\Delta E_{g}$ has been determined using the CNDO/2 method [12-14] and perturbation theory. This calculation has been carried out in three steps.

First we have performed a $\mathrm{CNDO} / 2$ calculation on the neutral molecule $R$ in order to obtain $E_{g}(\mathrm{R})$ and the corresponding wave-function. In the second step the position of the proton has been determined by calculating the molecular electrostatic potential [15] of the molecule R., following a procedure similar to that of Petrongolo and Tomasi [16]. The electrostatic potential gives a first order approximation of $\Delta E_{g}$, commonly called the Coulomb energy $\left(E_{\mathrm{C}}\right)$. By evaluating $E_{\mathrm{C}}$ at several points in space one or more minima may be found which correspond - to first order - to the sites of protonation in the molecule. This type of calculation is much less time consuming than minimization of $E_{g}\left(\mathrm{RH}^{+}\right)$by a full CNDO/ 2 calculation.

In the final step - with the proton placed at one of the $E_{C}$ minima - we have first carried the perturbation approach - of which $E_{\mathrm{C}}$ is the first order term - to higher order. In this way we obtain the induction energy $E_{1}$, resulting from polarization of the molecular charge distribution in the field of the proton $[17,18]$. It has been shown that reliable values for $E_{1}$ can be obtained, employing a slightly modified second order energy expression based on Brillouin-Wigner perturbation energy [19] (see Ref. [18] for further details). Secondly, polarization as well as charge transfer is taken into account by performing a CNDO/ 2 calculation on the protonated species, giving $E_{g}\left(\mathrm{RH}^{+}\right)$. Subtracting $E_{g}(\mathrm{R})$ from $E_{g}\left(\mathrm{RH}^{+}\right)$we obtain the gas phase protonation energy $\Delta E_{g}$.

However, it is well known that these protonation energies are overestimated by the CNDO/2 method $[4,16]$. Since they appear to be about $4 / 3$ times as large as the corresponding energies obtained from minimal basis set $a b$ initio calculations, we have scaled down our $\Delta E_{g}$ values by a factor $3 / 4$.

Having determined the various terms which contribute to $\Delta E_{l}$, the energy change in solution, it is necessary to make some assumptions before we can correlate $\Delta E_{l}$ with experimental $\mathrm{pK}_{\mathrm{a}}$ values. At $298^{\circ} \mathrm{K}$ the latter are related to the free energy difference in solution $\left(\Delta G_{l}\right)$ as follows:

$$
\Delta G_{l}=-R T \ln K_{a}=1.36 \mathrm{pK}_{\mathrm{a}}
$$

where $\Delta G_{l}$ is in $\mathrm{kcal} /$ mole.

If we assume that, apart from a symmetry factor, the entropy difference of the reaction is constant and that changes in volume can be neglected, Eq. (4) reduces to:

$$
\Delta E_{l}=1.36 \mathrm{pK}_{\mathrm{a}}^{\prime}+\text { constant }
$$

where $\mathrm{pK}_{\mathrm{a}}^{\prime}$ incorporates the symmetry factor mentioned above $\left(\mathrm{pK}_{\mathrm{a}}^{\prime}=\mathrm{pK}_{\mathrm{a}}-0.30\right.$ for the symmetrical diazanaphthalenes and $\mathrm{pK}_{\mathrm{a}}^{\prime}=\mathrm{pK}_{\mathrm{a}}$ otherwise). Since the solvation energy of the proton $\left(E_{s}\left(\mathrm{H}^{+}\right)\right)$is also constant, it is convenient to rewrite Eq. (5) as:

$$
-\Delta E=1.36 \mathrm{pK}_{\mathrm{a}}^{\prime}-E_{\mathrm{s}}\left(\mathrm{H}^{+}\right)+\mathrm{constant}
$$

where $\Delta E$ is defined by [cf. Eq. (2)]:

$$
\Delta E=\Delta E_{g}-E_{s}(\mathrm{R})+E_{s}\left(\mathrm{RH}^{+}\right)
$$




\section{Results and Discussion}

A difficulty in our calculations for the 12 azanaphthalenes is that the molecular structure is not known for all of them. We therefore assumed the "benzene" geometry for all molecules: $R_{\mathrm{CC}}=R_{\mathrm{CN}}=R_{\mathrm{NN}}=1.397 \AA, R_{\mathrm{CH}}=1.084 \AA$ and all angles $120^{\circ}$.

The results of the calculations are shown in Table 1 (for atom numbering see Fig. 1). Using these results we have examined how the $\mathrm{pK}_{\mathrm{a}}^{\prime}$ values correlate with $E_{\mathrm{C}}, E_{\mathrm{C}}+E_{\mathrm{I}}, \Delta E_{g}$, and $\Delta E$ in order to establish the relative importance of these terms.

Table 1. Protonation energy terms for azanaphthalenes. All energies in $\mathrm{kcal} / \mathrm{mole}$

\begin{tabular}{|c|c|c|c|c|c|c|}
\hline Compound & No. & ${ }^{-E_{C}}$ & $-E_{I}$ & $-\Delta E_{g} \quad a$ & $-\Delta \mathrm{E}$ & $\mathrm{pK}_{\mathrm{a}}^{\prime}$ \\
\hline $\begin{array}{l}\text { Cinnoline } \\
(1,2-\text { diazanaphthalene })\end{array}$ & $1 \alpha$ & $\begin{array}{l}88.35 \\
87.66\end{array}$ & $\begin{array}{l}75.00 \\
70.43\end{array}$ & $\begin{array}{l}256.41 \\
253.50\end{array}$ & $\begin{array}{l}290.85 \\
288.76\end{array}$ & 2.27 \\
\hline $\begin{array}{l}\text { Quinazoline } \\
(1,3 \text {-diazanaphthalene) }\end{array}$ & $2 \underset{\beta}{\alpha}$ & $\begin{array}{l}91.30 \\
85.84\end{array}$ & $\begin{array}{l}73.09 \\
72.17\end{array}$ & $\begin{array}{l}261.72 \\
256.96\end{array}$ & $\begin{array}{l}296.46 \\
292.34\end{array}$ & 3.43 \\
\hline $\begin{array}{l}\text { Quinoxaline } \\
(1,4-\text { diazanaphthalene })\end{array}$ & 3 & 77.44 & 74.20 & 258.17 & 293.12 & 0.26 \\
\hline $\begin{array}{l}1,5-\text { naphthyridine } \\
(1,5-\text { diazanaphthalene })\end{array}$ & 4 & 88.23 & 75.16 & 259.88 & 295.27 & 2.61 \\
\hline $\begin{array}{l}\text { 1,6-naphthyridine } \\
(1,6 \text {-diazanaphthalene })\end{array}$ & $5 \alpha$ & $\begin{array}{l}81.19 \\
83.32\end{array}$ & $\begin{array}{l}74.32 \\
70.87\end{array}$ & $\begin{array}{l}261.41 \\
258.44\end{array}$ & $\begin{array}{l}297.02 \\
294.00\end{array}$ & 3.78 \\
\hline $\begin{array}{l}\text { 1,7-naphthyridine } \\
\text { (1,7-diazanaphthalene) }\end{array}$ & $6 \begin{array}{l}\alpha \\
\beta\end{array}$ & $\begin{array}{l}78.75 \\
82.33\end{array}$ & $\begin{array}{l}73.79 \\
70.53\end{array}$ & $\begin{array}{l}260.06 \\
257.39\end{array}$ & $\begin{array}{l}295.57 \\
292.99\end{array}$ & 3.63 \\
\hline $\begin{array}{l}\text { 1,8-naphthyridine } \\
\text { (1,8-diazanaphthalene) }\end{array}$ & 7 & 103.10 & 74.37 & 262.67 & 297.42 & 3.09 \\
\hline $\begin{array}{l}\text { Phthalazine } \\
(2,3 \text {-diazanaphthalene })\end{array}$ & 8 & 81.08 & 70.41 & 257.44 & 292.19 & 3.17 \\
\hline $\begin{array}{l}2,6-\text { naphthyridine } \\
(2,6 \text {-diazanaphthalene })\end{array}$ & 9 & 88.23 & 71.41 & 256.68 & 293.21 & 3.18 \\
\hline $\begin{array}{l}\text { 2,7-naphthyridene } \\
(2,7-\text { diazanaphthalene })\end{array}$ & 10 & 90.11 & 71.56 & 257.69 & 294.04 & 3.43 \\
\hline $\begin{array}{l}\text { Quinoline } \\
\text { (1-azanaphthalene) }\end{array}$ & 11 & 82.96 & 72.18 & 263.78 & 298.60 & 4.94 \\
\hline $\begin{array}{l}\text { Isoquinoline } \\
\text { (2-azanaphthalene) }\end{array}$ & 12 & 96.26 & 72.99 & 258.93 & 294.10 & 5.40 \\
\hline
\end{tabular}

a these values have been scaled down by a factor $3 / 4$ (see text)

b for $\mathrm{pk}_{\mathrm{a}}$ values see Ref. [10]

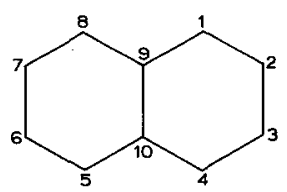

Fig. 1. Numbering of the positions in a naphthalene molecule 


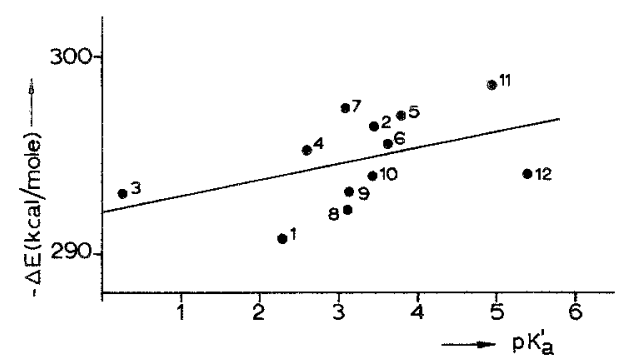

Fig. 2. Correlation between $\Delta E$ and $\mathrm{pK}_{\mathrm{a}}^{\prime}$ for azanaphthalenes. The numbers in the figure correspond to the numbers in Table 1

If we consider the Coulomb energy $E_{\mathrm{C}}$ we find hardly any correlation with $\mathrm{pK}_{\mathrm{a}}^{\prime}$, the correlation coefficient $c$ being 0.35 . Especially the large Coulomb energy of 1,8-naphthyridine is striking. The correlation becomes even worse if we include the induction energy $E_{\mathrm{r}}: c=0.23$. The protonation energy in the gas phase $\Delta E_{g}$ gives a correlation with the $\mathrm{pK}_{\mathrm{a}}^{\prime}$ values slightly better than that of the Coulomb energy $(c=0.41)$.

Inclusion of the solvation energy terms gives a further improvement $(c=0.46)$. The correlation line corresponding to $\Delta E$ is shown in Fig. 2. The slope of this line is 0.82 which is somewhat less than the expected value of 1.36 [cf. Eq. (6)]. The intercept is $292.1 \mathrm{kcal} / \mathrm{mole}$. This should be approximately equal to the solvation energy of the proton, as we expect the constant in Eq. (6) not to be larger than $10 \mathrm{kcal} / \mathrm{mole}$ [20]. Since the solvation energy of the proton is $261 \mathrm{kcal} / \mathrm{mole}$ [21], one may infer that the adjustment of $\Delta E_{g}$ (based on minimal basis set $a b$ initio calculations) still leads to slightly overestimated protonation energies (cf. Ref. [9]).

Although $\Delta E$ gives a better correlation than $E_{\mathrm{C}}, E_{\mathrm{C}}+E_{\mathrm{I}}$ or $\Delta E_{g}$, the final correlation $(c=0.46)$ is not satisfactory. We will now consider some possible sources of error which may be responsible for this poor correlation.

a) We have placed the proton at the minimum of the Coulomb energy. In further calculations this position is not changed, though we might expect the optimized geometry of the protonated molecule to be different, not only with regard to the proton position, but also as a consequence of some deformation of the reacting molecule. However, it would cost a tremendous amount of computation time to find this geometry.

b) Another, perhaps a more serious, error is that for all molecules we have used the "benzene" structure, which may differ considerably from the experimental structure. We have investigated this error by performing similar calculations on four azabenzenes for which the experimental structure is known [22-25]. The various contributions to $\Delta E$ for both the "benzene" structure and the experimental structure have been determined in the same way as before.

The results are given in Table 2 and Fig. 3. From the correlation lines given in Fig. 3, which refer to $\Delta E$ versus $\mathrm{pK}_{\mathrm{a}}^{\prime}$, it is seen that the influence of the structure is surprisingly small as far as the slope is concerned, both slopes being 0.89 . However, the correlation coefficients differ considerably $-c=0.70$ and 
Table 2. Protonation energy terms for azabenzenes. All energies in $\mathrm{kcal} / \mathrm{mole}$

\begin{tabular}{|c|c|c|c|c|c|c|}
\hline Compound & No. & $-E_{C}$ & $-E_{I}$ & $-\Delta E_{g} c$ & $-\Delta E$ & $\mathrm{pK}_{\mathrm{a}}^{\prime \prime} \mathrm{d}$ \\
\hline $\begin{array}{l}\text { Pyridine } \\
\text { (1-azabenzene) }\end{array}$ & $\begin{array}{l}13^{\mathrm{a}} \\
13^{\mathrm{b}}\end{array}$ & $\begin{array}{l}83.77 \\
83.59\end{array}$ & $\begin{array}{l}67.83 \\
67.33\end{array}$ & $\begin{array}{l}252.36 \\
245.78\end{array}$ & $\begin{array}{r}297.49 \\
290.94\end{array}$ & 5.23 \\
\hline $\begin{array}{l}\text { Pyridazine } \\
(1,2 \text {-diazabenzene })\end{array}$ & $\begin{array}{l}14_{\mathrm{b}}^{\mathrm{a}} \\
14^{\mathrm{b}}\end{array}$ & $\begin{array}{l}84.65 \\
81.08\end{array}$ & $\begin{array}{l}68.96 \\
66.33\end{array}$ & $\begin{array}{l}246.31 \\
241.98\end{array}$ & $\begin{array}{l}291.02 \\
287.18\end{array}$ & 2.03 \\
\hline $\begin{array}{l}\text { Pyrimidine } \\
\text { ( } 1,3 \text {-diazabenzene) }\end{array}$ & $\begin{array}{l}15^{\mathrm{a}} \\
15^{\mathrm{b}}\end{array}$ & $\begin{array}{l}83.71 \\
77.50\end{array}$ & $\begin{array}{l}68.96 \\
67.96\end{array}$ & $\begin{array}{l}249.08 \\
242.50\end{array}$ & $\begin{array}{l}294.68 \\
288.08\end{array}$ & 1.00 \\
\hline $\begin{array}{l}\text { Pyrazine } \\
(1,4-\text { diazabenzene })\end{array}$ & $\begin{array}{l}16^{\mathrm{a}} \\
16^{\mathrm{b}}\end{array}$ & $\begin{array}{l}78.56 \\
70.91\end{array}$ & $\begin{array}{l}68.78 \\
66.58\end{array}$ & $\begin{array}{l}247.17 \\
240.26\end{array}$ & $\begin{array}{l}292.75 \\
286.10\end{array}$ & 0.35 \\
\hline
\end{tabular}
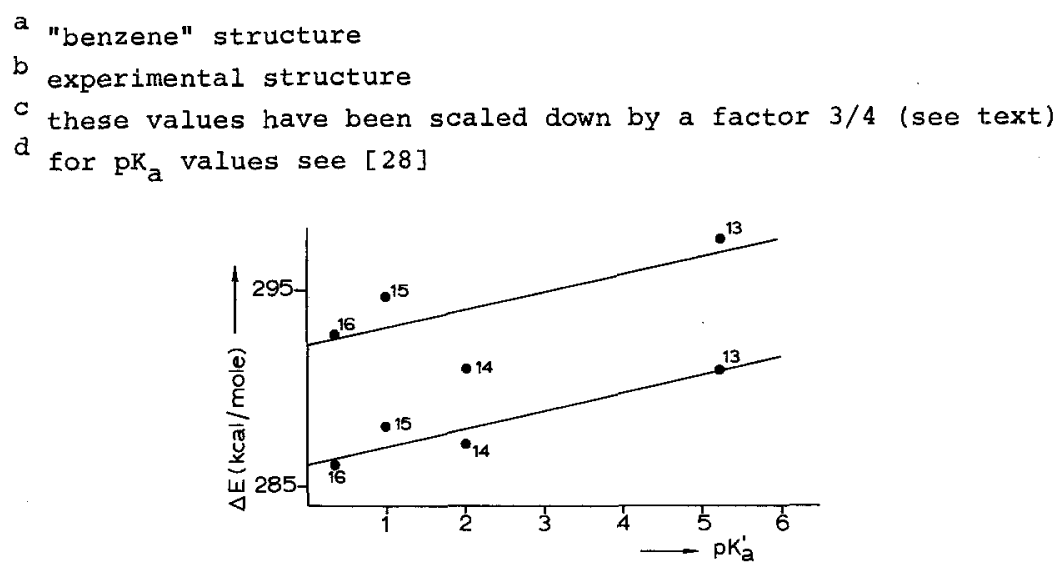

Fig. 3. Correlation between $\Delta E$ and $\mathrm{pK}_{\mathrm{a}}^{\prime}$ for azabenzenes. The upper line corresponds to the azabenzenes with "benzene" geometry, the lower line to the azabenzenes with experimental geometry. For numbering see Table 2

$c=0.93$ - thus underlining the importance of the use of experimental geometries.

This difference in correlation coefficients is mainly due to the large deviation found for pyridazine ("benzene" structure). This is not surprising, since the departure from the "benzene" structure will be most pronounced when two nitrogen atoms are attached to each other. In the case of diazanaphthalenes the same phenomenon may be noticed for cinnoline and phthalazine (see Fig. 2).

Reasonable correlations for azabenzenes (experimental structure) are also obtained between $\mathrm{pK}_{\mathrm{a}}^{\prime}$ and $E_{\mathrm{C}}, E_{\mathrm{C}}+E_{\mathrm{I}}$ and $\Delta E_{g}: c=0.84, c=0.84$ and $c=0.95$ respectively. These results indicate that for correlation with $\mathrm{pK}_{\mathrm{a}}^{\prime}$ values within $\mathrm{a}$ given series the induction and solvation energy terms are relatively unimportant.

It is seen from Fig. 2 and Fig. 3 that the correlation line of the azanaphthalenes and that of the azabenzenes ("benzene" structure) nearly coincide (as they should): both lines have the same intercept $(292.1 \mathrm{kcal} / \mathrm{mole})$ and about the same slope (0.82 and 0.89 respectively). This would not be the case if the solvation energy - which is largely dependent on the size of the molecules - had been omitted, a fact which has been noted before [26]. 
c) In the case of the asymmetrical diazanaphthalenes an additional difficulty is the fact that two different protonation sites are possible (we have always used the lowest energy value for our correlations). For cinnoline and quinazoline our results clearly indicate position 1 (the $\alpha$-position) as the most favourable site of protonation. However, for 1,6- and 1,7-naphthyridine the Coulomb energy favours position 6 and 7 respectively (the $\beta$-position), whereas according to $\Delta E_{g}$ and $\Delta E$, protonation will take place at the $\alpha$-position. A similar discrepancy between $E_{\mathrm{C}}$ and $\Delta E_{g}$ is sometimes encountered in ab initio calculations (see e.g. the results for cyclopropene in Ref. [27]).

Experimental work to determine the actual site of protonation is in progress.

\section{Conclusions}

Our calculations on azanaphthalenes have resulted in a rather poor correlation between $\Delta E$ and $\mathrm{pK}_{\mathrm{a}}^{\prime}$. However, similar calculations on azabenzenes have shown that to a large extent this may be due to the lack of experimental geometries in the former case.

For correlation with $\mathrm{pK}_{\mathrm{a}}^{\prime}$ values within a series of structurally similar molecules one should use either the Coulomb energy or - preferably - the gas phase protonation energy. The induction and solvation energy terms have been shown to be relatively unimportant.

With regard to the site of protonation in the asymmetrical diazanaphthalenes our results indicate that for cinnoline and quinazoline the $\alpha$-position is the most favourable site of attack. However, for 1,6- and 1,7-naphthyridine the present results are not conclusive.

Acknowledgement. We wish to thank Prof. Dr. D. Feil and Dr. F. B. van Duijneveldt for critically reading the manuscript.

The investigations were supported in part by the Netherlands Foundation for Chemical Research (SON) with financial aid from the Netherlands Organization for the Advancement of Pure Research (ZWO).

\section{References}

1. Longuet-Higgins, H.C.: J. Chem. Phys. 18, 275 (1950)

2. Chalvet, O., Pages, M., Roux, M., Buu-Hoi, N.P., Royer, R.: J. Chim. Phys. 51, 548 (1954)

3. Pullman, A., Nakajima, T.: J. Chim. Phys. 55, 793 (1958)

4. Schuster, P.: Theoret. Chim. Acta (Berl.) 19, 212 (1970)

5. Kollmar,H., Smith,H.O.: Chem. Phys. Letters 5, 7 (1970)

6. Leibovici, C.: Intern. J. Quantum Chem. 8, 193 (1974)

7. Hopkinson, A.C., Holbrook, N. K., Yates, K., Csizmadia, I.G.: J. Chem. Phys. 49, 3596 (1968)

8. Lathan, W.A., Hehre, W.J., Curtiss, L.A., Pople, J.A.: J. Am. Chem. Soc. 93, 6377 (1971)

9. Hopkinson, A.C., Csizmadia, L. G.: Can. J. Chem. 52, 546 (1974)

10. van den Ham, D. M.W.: private communication

11. Hylton,J., Christoffersen, R.E., Hall,G.G.: Chem. Phys. Letters 24, 501 (1974)

12. Pople,J.A., Santry, D. P., Segal,G. A.: J. Chem. Phys. 43, S 129 (1965)

13. Pople,J.A., Segal, G. A.: J. Chem. Phys. 43, S 136 (1965)

14. Pople,J.A., Segal,G.A.: J. Chem. Phys. 44, 3289 (1966)

15. Bonaccorsi, R., Scrocco, E., Tomasi, J.: J. Chem. Phys. 52, 5270 (1970) 
16. Petrongolo, C., Tomasi, J.: Chem. Phys. Letters 20, 201 (1973)

17. van Duijneveldt,F.B.: Thesis, University of Utrecht 1969

18. Koster,J.L.: Thesis, University of Utrecht 1975; copies are available on request

19. Hameka, H.F.: Introduction to quantum theory. New York: Harper \& Row 1967

20. Arnett, E. M., Jones III, F.M., Taagepera, M., Henderson, W.G., Beauchamp, J.L., Holtz, D., Taft, R.W.: J. Am. Chem. Soc. 94, 4724 (1972)

21. Kebarle, P., Searles, S. K., Zolla, A., Scarborough, J., Arshadi, M.: J. Am. Chem. Soc. 89, 6393 (1967)

22. Bak, B., Hansen-Nygaard, L., Rastrup-Andersen, J.: J. Mol. Spectry. 2, 361 (1958) (pyridine)

23. Innes, K. K., Lukas, R. M., Jr.: J. Mol. Spectry. 24, 247 (1963) (pyridazine)

24. Wheatley, P.J.: Acta Cryst. 13, 80 (1960) (pyrimidine)

25. Merrit,J.A., Innes, K. K.: Spectrochim. Acta 16, 945 (1960) (pyrazine)

26. Daudel,R.: Quantum theory of chemical reactivity. Boston: D. Reidel Publishing Company 1967

27. Ghio, C., Tomasi, J.: Theoret. Chim. Acta (Berl.) 30, 151 (1973)

28. Albert, A.: Physical methods in heterocyclic chemistry, Vol. I. New York: Academic Press 1963

Dr. D. van der Meer

Chemical Physics Laboratory

Twente University of Technology

Postbus 217

Enschede, The Netherlands 